\title{
Wisdom in Education
}

Volume 1 | Issue 1

Article 1

$5-1-2005$

\section{Wisdom, Intelligence, and Creativity Synthesized.}

Susan Daniels

California State University San Bernardino, sdaniels@csusb.edu

Follow this and additional works at: https://scholarworks.lib.csusb.edu/wie

Part of the Art Education Commons, Curriculum and Instruction Commons, Educational Psychology Commons, Elementary Education and Teaching Commons, Gifted Education Commons, Junior High,

Intermediate, Middle School Education and Teaching Commons, and the Special Education and Teaching Commons

\section{Recommended Citation}

Daniels, Susan (2005) "Wisdom, Intelligence, and Creativity Synthesized.," Wisdom in Education: Vol. 1 : Iss. 1 , Article 1.

Available at: https://scholarworks.lib.csusb.edu/wie/vol1/iss1/1

This Article is brought to you for free and open access by CSUSB ScholarWorks. It has been accepted for inclusion in Wisdom in Education by an authorized editor of CSUSB ScholarWorks. For more information, please contact scholarworks@csusb.edu. 


\title{
Wisdom, Intelligence, and Creativity Synthesized.
}

\author{
Abstract \\ Wisdom, as explored by Sternberg is the application of successful intelligence and creativity. For thirty \\ years, Dr. Sternberg has been a vocal critic of narrow conceptions of intelligence. In this recent work, he \\ argues that a more comprehensive view of intelligence must go beyond the psychometrically based, IQ- \\ driven views predominant in the last century. \\ Keywords \\ wisdom, intelligence, creativity \\ Author Statement \\ Dr Susan Daniels is a professor in the College of Education at California State University San Bernardino.
}




\section{Wisdom, Intelligence, and Creativity Synthesized}

by Susan Daniels

California State University, San Bernardino

Wisdom, as explored by Sternberg (2003) in Wisdom, Intelligence, and Creativity Synthesized, is described as "the application of successful intelligence and creativity as mediated by values toward the achievement of a common good through a balance among (a) intrapersonal, (b) interpersonal, and (c) extrapersonal interests, over (a) short and (b) long terms, in order to achieve a balance among (a) adaptation to existing environments, (b) shaping of existing environments, and (c) section of new environments" (p. 152). For thirty years, Dr. Sternberg has been a vocal critic of narrow conceptions of intelligence. In this recent work, he argues that a more comprehensive view of intelligence must go beyond the psychometrically based, IQ-driven views predominant in the last century.

In addition to the analytical, linguistic and quantitative frameworks addressed by the intelligence and standardized testing industry, Sternberg argues, a comprehensive view of intelligence must take into account one's creative abilities - including the ability to go beyond given information to develop new insight and perspectives in reformulating old problems. And a more comprehensive theory of intelligence must take into account wisdom specifically people's abilities to weigh options carefully and act prudently.

Professor Sternberg elucidates and elaborates these views while presenting a thorough chronicle of the development of notions of intelligence over the past 100 year. An overview of all major theories of intelligence is presented, from the early development of the Stanford-Binet intelligence tests and general concepts of intelligence to Gardner's theory of multiple intelligences and his own theory of successful intelligence - which includes three clusters of abilities: analytical, creative and practical. He emphasizes the role of creativity in the development of intelligence and wisdom such that those decisions which are wisest and that move our societies and individuals forward are not necessarily - and in fact frequently are not - the most obvious or commonly supported. As such, creativity is defined as the "ability to produce work that is novel. original. unexpected, high in quality and appropriate" (p.89) and that last element appropriateness - serves to further solidify the connection with wisdom. 
Wisdom, says Sternberg, can be defined as the "power of judging rightly and following the soundest course of action, based on knowledge, experience, understanding, etc." (p. 147). In this vein, he further elaborates the implications of integrating the concepts of wisdom and creativity with intelligence for psychologists and educators alike - linking the development of intelligence, creativity and wisdom with higher order thinking, synthesis and evaluation. To cultivate our students' potentials most fully, according to this theory, we must teach for and cultivate their potential for wisdom. As such, Dr. Sternberg lists 16 principles for teaching for wisdom (see sidebar) and describes a twelve-week wisdom curriculum in development at Yale University. Wisdom, he asserts, can be practiced; wisdom can be fostered. Said best in his own words: "Wisdom is not just a way of thinking about things; it is a way of doing things. If people wish to be wise, they have to act wisely, not just think wisely. We can all do this. Whether we do is our choice" (p. 188).

Certainly, Wisdom, Intelligence, and Creativity Synthesized presents information and insights that both inform and align with the California State University, San Bernardino - College of Education mission to develop wise educators. And, Wisdom, Intelligence, and Creativity Synthesized will serve as a useful reference as we continue to explore notions of Wisdom in Education in upcoming issues.

\section{Reference}

Sternberg, R. J. (2003). Wisdom intelligence and creativity synthesized. NY: Cambridge University Press.

\section{Sixteen Principles of Teaching for Wisdom}

1. Explore with students the notion that conventional abilities and achievements are not enough for a satisfying life. Many people become trapped in their lives and, despite feeling conventionally successful, feel that their lives lack fulfillment. Fulfillment is not an alternative to success, but is an aspect of it that, for most people, goes beyond money, promotions, large houses and so forth. 
2. Demonstrate how wisdom is critical for a satisfying life. In the long run, wise decisions benefit people in ways that foolish decisions never do.

3. Teach students the usefulness of interdependence $-a$ raising tide raises all ships; a falling tide can sink them.

4. Role-model wisdom because what you do is more important than what you say. Wisdom is action-dependent and wise actions need to be demonstrated.

5. Have students read about wise judgments and decision making so they understand that there are such means of judging and decision making.

6. Help students to recognize their own interests those of other people, and those of institutions.

7. Help students to balance their own interests, those of other people, and those of institutions.

8. Teach students that the "means" by which the end is obtained matters, not just the end.

9. Help students learn the roles of adaptation, shaping, and selection, and how to balance them. Wise judgments are 
dependent in part on selecting among these environmental responses.

10. Encourage students to form, critique, and integrate their own values in their thinking.

11. Encourage students to think dialectically, realizing that both questions and their answers evolve over time, and that the answer to an important life question can differ at different times in one's life (such as whether to go to college).

12. Show students the importance of dialogical thinking, whereby they understand interests and ideas from multiple points of view.

13. Teach students to search for and then try to reach the common good - a good where everyone wins, not only those with whom one identifies.

14. Encourage and reward wisdom.

15. Teach students to monitor events in their lives and their own thought processes about these events. One way to recognize others' interests is to begin to identify one's own. 
16. Help students understand the importance of inoculating oneself against the pressures of unbalanced self-interest and small-group interest.

Excerpted from: Sternberg, R. J. (2003). Wisdom, intelligence and creativity synthesized. NY: Cambridge University Press. 